\title{
FATOR TRABALHO NO MANEJO RURAL NO SEMIÁRIDO NORDESTINO, BRASIL
}

\author{
RURAL WOMEN MANAGEMENT IN THE NORTHEASTERN BRAZILIAN SEMIARID
}

\begin{abstract}
Vidal, D.L. ${ }^{1 *}$
'Laboratório de Estudos em Sistemas Semiáridos. Faculdade de Veterinária da Universidade Estadual do Ceará. Fortaleza. Ceará. Brasil. *dea.vidal@pesquisador.cnpq.br; lesisa2008@gmail.com
\end{abstract}

\section{PaLAVRAS CHAVE ADICIONAIS}

Mulher rural. Gênero. Áreas desfavorecidas.

\section{RESUMO}

Analisa-se a participação micro-econômica da mulher de diferentes comunidades rurais no Município de Tauá, Microrregião do Sertão dos Inhamuns, Ceará (Comunidades do Junco, Tapera, Lustal 1, Lustal 2, Tiassol e Queimadas), no que diz respeito ao manejo de tarefas rurais. As Unidades de Produção Agrária Familiar (UPAF) estudadas nessas comunidades representam $75,7 \%$ das mulheres participantes $(n=103)$ do Projeto de Pesquisa. O total de UPAFs residentes nas 6 comunidades sob estudo ascende a 305 , portanto, o presente trabalho abrangeu $25,5 \%$ das mulheres rurais do distrito. Os dados coletados in situ através de questionários, foram submetidos à análise estatística descritiva, multifatorial e de variância. A mulher rural dessas comunidades encontra-se predominantemente na faixa de 45,52 anos com prole em idade escolar e não possui educação formal. A mulher surge como principal responsável pelas aves, suínos e horta-pomar e está envolvida em atividades com o roçado e com gado ruminante minimamente. Como os não ruminantes são considerados nessas comunidades de menor valor quando comparados com ruminantes, os cônjuges das mulheres estão menos interessados em intervir com o controle feminino sobre aqueles meios de produção, viabilizando-se assim o livre manejo desses recursos por parte da mulher. Evidencia-se a alta importância do trabalho feminino no funcionamento das UPAFs em cinco dessas comunidades (menos Tiassol) situadas no semiárido da Região Nordeste do Brasil.

\section{AdDitionAL KEYWORDS}

Rural women. Gender. Lessfavoured areas.

\section{SUMMARY}

It is analyzed women micro-economic participation of six different agricultural communities in the City of Tauá, Inhamuns Semiarid Microregion, Ceará State, Brazil (Communities of Junco, Tapera, Lustal I, Lustal II, Tiassol and Queimadas), in relation to the rural tasks management. The Family Farm Production Units (FPUs) of these rural women represent $75.66 \%$ of the participants $(n=103)$ of the project. The total number of FPUs in the 6 communities studied is 305 , therefore, the current study encompassed $24.59 \%$ of rural women in these communities. The in situ collected data through questionnaires, have been submitted to the frequency, multifactorial and variance statistical analyses. The rural women of these communities are predominantly 45.52 years old with school age children and they do not possess formal education. The partners of women are less interested in interfering in female control of these means of production because they are considered to be of less value in comparison to roçado and ruminant management. Thus, the women can freely manage these resources for family needs. They appear as main responsible for the fowl, swines and vegetables garden-orchard and are minimaly involved in activities with cultivation and ruminant cattle. From these results the importance of female work is clear for the functioning of the family farm production units in five rural communities (with the exception of Tiassol) being studied in the semiarid region in the Northeast of Brazil. 


\section{INTRODUÇÃO}

A superação das disparidades de gênero ao nível político-econômico nos ambientes rural e urbano, foi colocada como objetivo a ser atingido mundialmente até 2015 pela ONU (2000). No entanto, o mundo da mulher agrária continua sofrendo tradicionalmente um desinteresse evidente por parte do restante dos setores sociais e econômicos. A divisão tradicional de gênero esconde as proporções da participação econômica da mulher na construção da riqueza rural e de seu conseqüente desenvolvimento.

O trabalho feminino tem sido comumente subestimado no setor agrário devido a não ser considerado como primário e não ser comumente pago para produzir alimentos de consumo e de comércio da Unidade Familiar (FAO, 1996-2001). No entanto, em países da periferia capitalista, a posição econômica da mulher rural vincula-se há décadas e diretamente, a seu papel na produção e preparação de alimentos (Banco Mundial, 1980), entrelaçando-se, portanto, à nutrição e segurança alimentar de populações pobres (Pinstrup-Andersen e Marito, 1984).

O Sertão na Região Nordeste do Brasil é caracterizado por ecossistemas marginais e ameaçados e se destaca pela grande diversidade de paisagens semiáridas e costumes tradicionais. Sua história, marcada pelo latifúndio e uma intensa desigualdade não somente econômica, evidencia o preconceito existente em relação a atividades realizadas por mulheres. No Sertão, a seca aliada ao latifúndio e a discriminação de gênero provocam graves efeitos que atingem principalmente a população rural pobre e nessa, mais diretamente as mulheres. No Estado nordestino do Ceará, especialmente, essa questão assume caráter estratégico, já que foi constatado que houve diminuição da porcentagem de mulheres vivendo em áreas rurais do interior, incluindo as amplas áreas sertanejas (IPECE, 2008).
Tem sido estabelecido por vários autores (Benevides, 2004; Rua e Abramovay, 2003; Shalander, 2008; Vidal, 1995a, 1995b, 1995c e Vidal, 2009, entre outros) que o envolvimento da mulher rural na produção da agropecuária tem significado para o desenvolvimento da economia da respectiva região e por extensão do país. A população feminina brasileira apresenta uma taxa crescente de participação no trabalho. No Estado do Ceará especificamente, esse indicador apresentou valor de aproximadamente $48 \%$ em 1996, chegando a $55 \%$ em 2005, e decresceu para aproximadamente 53\% em 2006 (IPECE, 2008). Portanto, a taxa de participação feminina no mercado de trabalho urbano e rural cresceu $10,3 \%$ entre 1996 e 2006 , caracterizando-se com uma das principais transformações estruturais que o mercado de trabalho cearense apresentou nas últimas décadas. O comportamento da renda familiar para famílias chefiadas por homens ou mulheres no Ceará no período de 1996 a 2006 é evidenciado pelo IPECE (2008). Para as famílias chefiadas por homens, a renda total familiar apresentou sucessivas quedas até o ano de 2003 (de R \$ 975,2 a R \$ 824,5)*, voltando a crescer a partir deste ano. Por outro lado, as famílias chefiadas por mulheres apresentaram uma tendência de crescimento da renda familiar total (de $\mathrm{R} \$ 668,1$ a $\mathrm{R} \$ 804,50$ ) ao longo do mesmo período acima citado, embora tenham sido observadas oscilações em seus valores. Todavia, o diferencial de renda familiar em favor das famílias chefiadas por homens em relação às chefiadas por mulheres é positivo, mas decrescente ao longo do período analisado. Apesar do crescimento na conscientização da questão de gênero no Brasil e no mundo, dados sistematizados sobre trabalhos realizados por mulheres rurais e sua contribuição para o desenvolvimento da economia local são escassos. Ademais, esses rareados trabalhos parece haverem permanecido longe

$* 1 \mathrm{US} \$=1,57 \mathrm{R} \$$. 
da gestão das políticas públicas no Nordeste do Brasil e particularmente no Estado do Ceará. Nesse último para o Município de Tauá - Região dos Inhamuns (IBGE, 2008) e que inclui a zona de estudo, conhecem-se apenas os dados quantitativos municipais da população de mulheres rurais aptas a realizar trabalhos agropecuários que é de 12527 , representando $45,76 \%$ do total da população estimada em toda área rural municipal. Aproximações à dinâmica do trabalho rural feminino em unidades familiares da Região dos Inhamuns, Ceará, não foram realizadas até o momento, constituindo-se, portanto em fértil e desafiante campo de pesquisa.

$O$ estudo do coletivo feminino na agricultura dos Sertões semiáridos do Estado do Ceará, supõe considerar a complexidade dos fatores que interatuam no momento de reconhecer micro-economicamente a natureza da participação do trabalho da mulher, já que esse estudo se interlaça à problemática da feminização da pobreza no Brasil (Câmara Federal Brasileira, 2004) e à revalorização econômica e social do trabalho familiar e camponês na atual gestão do Governo do Brasil.

Nesse trabalho, pretende-se iniciar o estudo da participação micro-econômica feminina para a manutenção de unidades agrárias familiares em zonas rurais semiáridas no Ceará, localizadas no Sertão. Para tal, os objetivos específicos do presente estudo foram: (i) identificar os fatores estatísticos explicativos das atividades femininas mais importantes; (ii) descrever e comparar as características sociológicas gerais das mulheres rurais entre as comunidades e (iii) identificar e comparar os trabalhos rurais mais relevantes realizados pelas mulheres nas comunidades.

\section{METODOLOGIA}

O estudo se situou no Distrito do Baixo Trici, localizado no Município de Tauá, Sertão dos Inhamuns, Estado do Ceará,
Brasil, e englobou setenta e cinco mulheres distribuídas em seis comunidades rurais diferentes, a saber: Junco $(n=16)$, Tapera $(n=16)$, Lustal $1(n=16)$ e Lustal $2(n=9)$, Tiassol $(n=9)$ e Queimadas ( $n=9)$. Genericamente as atividades econômicas dessas comunidades rurais estão vinculadas à produção de leite e queijo bovino, hortaliças e carne de pequenos ruminantes (Vidal, 2009).

As Unidades de Produção Agrária Familiar (UPAF) dessas mulheres rurais representam $75,7 \%$ das participantes $(n=103)$ do projeto de pesquisa Autosustentação econômico-social de comunidades rurais através de cabras leiteiras naturalizadas em região semiárida dos Inhamuns, Ce, financiado pelo $\mathrm{CNPq}$ (Conselho Nacional de Desenvolvimento Científico e Tecnológico, Ministério de Ciência e Tecnologia do Governo do Brasil). As restantes UPAFs que participaram do projeto não se encontravam disponíveis ou se tratavam de unidades apenas com homens solteiros ou viúvos. O total de UPAFs residentes nas 6 comunidades sob estudo ascende a 305 , portanto, o presente trabalho abrangeu $25,5 \%$ das mulheres rurais do distrito.

A coleta de dados originais e in situ foi realizada através de questionário semiestruturado individualizado aplicado diretamente à mulher rural e reuniu informações sobre: (i) características sociológicas gerais: idade (anos), educação (\% por comunidade) e fase familiar; (ii) responsabilidades na agricultura (ou seja, no roçado); (iii) responsabilidades na pecuária bovina, caprina, ovina e de aves e suínos; (iv) responsabilidades na produção de horta e extrativismo de pomar e, (v) responsabilidades em tarefas de gestão e administração da UPAF, ou seja, outros trabalhos. A discriminação detalhada dos níveis educacionais, das fases familiares e da composição de cada uma das responsabilidades nas tarefas encontrase respectivamente nas tabelas apresentadas no item resultados.

Esses questionários foram aplicados 
durante o período de Março a Outubro de 2008 pela equipe do Laboratório de Estudos em Sistemas Semiáridos (Lesisa) da Faculdade de Veterinária da Universidade Estadual do Ceará, Brasil.

Foram identificados através da análise multivariada de componentes principais (ACP) com distância euclidiana (parâmetros: alpha $=0,5 ;$ beta $=0,5$ e gama $=0,9)$ (MartínGuzman, 1988) os fatores que explicam os principais trabalhos agrícolas, pecuários e/ ou de gestão realizados pelas mulheres rurais. Para o conjunto de mulheres de cada comunidade rural foi realizada análise

Tabela I. Contribuição das principais variáveis aos primeiros três fatores obtidos na ACP para mulheres com alta freqüencia em trabalho com aves, suínos e tarefas manuais na horta-pomar. (Main variables contribution to the three factors of the PCA for women with swine, fowl and vegetable gardenorchard tasks high frequency).

Coeficientes dos autovetores

Fator 1 Fator 2 Fator 3

\begin{tabular}{lccc}
\hline Aves & & & \\
$\quad$ alimentação & $-0,005$ & 0,026 & 0,557 \\
$\quad$ limpeza & $-0,022$ & 0,062 & 0,565 \\
$\quad$ vigilância & $-0,015$ & 0,059 & 0,564 \\
$\begin{array}{l}\text { Suínos } \\
\quad \text { reprodução }\end{array}$ & 0,140 & 0,484 & $-0,064$ \\
$\quad$ limpeza & 0,125 & 0,495 & $-0,032$ \\
$\quad$ vigilância & 0,125 & 0,495 & $-0,032$ \\
Horta & & & \\
$\quad$ limpeza ervas & $-0,355$ & 0,132 & 0,018 \\
$\quad$ semeadura & $-0,361$ & 0,090 & 0,037 \\
$\quad$ irrig.manual & $-0,339$ & 0,100 & $-0,024$ \\
CF & 39,490 & 22,140 & 18,420 \\
VA & 39,490 & 61,630 & 80,060 \\
Autovalor & 6,3184 & 3,5429 & 2,9479 \\
AA & 6,3184 & 9,8612 & 12,8091 \\
\hline
\end{tabular}

CF: Contribuição ao fator (\%); VA: Variância acumulada (\%); AA: Autovalor acumulado; Parâmetros alpha e beta $=0,50$, gama $=0,90$; Método de distância euclidiana; Phi $=0,441637$, $\log ($ Det $/ R)=56,5242212$; Barlett test $=3834,23$; $\mathrm{p}<0,00000$. descritiva sobre a repartição das tarefas na UPAF. Essa análise descritiva incluiu estudo de freqüência (Daniels, 1984) de cada um dos critérios acima descritos. Na seqüência foi realizada comparação desses critérios entre as comunidades utilizando-se ANOVA-teste de Kruskal-Wallis para as variáveis quantitativas e tabelas de contingência e qui-quadrado para as qualitativas. As análises estatísticas de distribuição de freqüências foram implementadas com programa Excel 5.0 e as ANOVAs e a ACP por intermédio do programa BioEstat 5.0.

\section{RESULTADOSEDISCUSSÃO}

\section{FATORES QUE EXPLICAM AS DIFERENÇAS ENTREASMULHERES CAMPONESAS}

O trabalho feminino mais relevante foi identificado junto aos animais suínos, aves e atividades na horta-pomar através da análise de componentes principais (ACP) para classificar as mulheres camponesas. A ACP reduziu para nove o número original de dezesseis variáveis pela identificação daquelas que estão correlacionadas, permitindo identificar os principais fatores relacionados às mulheres rurais com alta freqüência de trabalho em não ruminantes e horta-pomar (tabela I). Os primeiros três fatores foram escolhidos porque, em conjunto, explicam a maior proporção da variância original $(80,06 \%)$ e apresentam Eigenvalues maiores que 1 . O F1, que contribui com $39,40 \%$ da variância explicada sobre as diferenças entre as mulheres

Tabela II. Acesso das mulheres rurais à educaçãoformal $(n=75)$. (Rural women access to the formal education $(n=75))$.

\begin{tabular}{lcc}
\hline Educação (\%) $(p<0,0001)$ & Sim & Não \\
\hline Ensino informal & 82,67 & 17,33 \\
Ensino fundamental & 6,67 & 93,33 \\
Ensino médio & 5,33 & 94,67 \\
Ensino superior & 5,33 & 94,67 \\
\hline
\end{tabular}


Tabela III. Idade média das mulheres rurais por comunidades. (Rural women average age by communities).

\begin{tabular}{lcc} 
Comunidades* $^{*}$ & $\begin{array}{c}\text { Mulheres } \\
(\mathrm{n})\end{array}$ & $\begin{array}{c}\text { Idade média } \\
\text { (anos) }\end{array}$ \\
Tapera & 16 & 43,63 \\
Lustal 1 & 16 & 43,56 \\
Lustal 2 & 9 & 40,11 \\
Queimadas & 9 & 43,11 \\
Junco & 16 & 51,25 \\
Tiassol & 9 & 51,44 \\
Total & 75 & 45,52 \\
\hline
\end{tabular}

${ }^{*} \mathrm{p}=0,1958$

rurais responsáveis por aves, suínos, hortapomar e trabalhos administrativos (outros trabalhos), identifica a senhoras que por não realizarem atividades de semeadura limpeza de ervas daninhas e/ou pulgões e irrigação manual, realizam as outras atividades com horta, ou seja, o manejo manual do solo na adubação, na retirada manual de pragas e na colheita. O segundo fator explica $22,14 \%$ dessa variância e reflete o manejo com suínos, identificando a mulheres responsáveis pela vigilância limpeza e reprodução desses animais e o terceiro e último fator, que absorve 18,42 da inércia, se refere ao manejo avícola e reflete o trabalho feminino nas tarefas de sanidade alimentação e de vigilância de aves de curral.

\section{ASPECTOS SOCIOLÓGICOS}

Resultados empíricos obtidos para um grande número de paises Árabes e da África Sub-Sahariana $(n=40)$ indicam que as desigualdades de gênero tiveram um efeito estatisticamente robusto e significativo sobre o analfabetismo feminino (Baliamoune-Lutz e McGillivray, 2009). No presente estudo foi observado que do total de mulheres rurais, $82,67 \%(n=62)$ não tiveram acesso algum à educação formal (tabela II). As restantes, escassamente iniciaram ou terminaram o ensino fundamental, o médio ou o superior $(6,67 ; 5,33$ e
$5,33 \%$ respectivamente em relação ao número total $(n=75), p<0,0001)$. Tais evidências corroboram os achados de Fischer (2001, 2002a e 2002b) e Fisher et al.(2003) para mulheres rurais no Estado Nordestino de Pernambuco e de Benevides (2004) para o Estado Nordestino da Bahia, ambos incluídos no Semiárido Brasileiro. Ademais, esses resultados no Brasil, são consistentes com os encontrados há uma década, para outra região semiárida, no caso, o vale médio do rio Ebro (Aragón) Espanha, onde o grau de formação educacional feminino para 75 mulheres estudadas revelou que $69,75 \%$ não haviam alcançado o EGB completo, ou seja, o ensino geral básico (Vidal, 1995c). Assim, se demonstra a mesma tendência inquietante, anteriormente presente em Aragón, nessa região frágil ecologicamente e desfavorecida socioeconomicamente do Brasil nos dias de hoje. Considerando as importantes e positivas mudanças ocorridas no âmbito da União Européia (Osakabe, 2000) à qual pertence a Espanha, se observa que apesar dos esforços inauditos do atual Governo do Brasil em relação à alfabetização por intermédio da parceria do Ministério da Educação com a Organização NãoGovernamental Alfabetização Solidária (Esteves, 2002; Furlan, 2007), o coletivo feminino dessa parte do semiárido brasileiro tem se incluído fracamente.

A mulher rural nordestina funciona como um elemento-chave não apenas para a sobrevivência dos indivíduos, mas também para a transmissão da cultura, do capital econômico, para a proteção e socialização de seus componentes e de solidariedade entre gerações (Santos, 2007). A maioria das mulheres sob estudo $(n=50)$ possui menos de 45,52 anos em média e se situam nas comunidades de Tapera, Lustal 1, Lustal 2 e Queimadas (tabela III). No entanto, as diferenças entre as idades médias por comunidade não são significativas $(\mathrm{p}=$ $0,1958)$. Em relação às fases familiares (tabela IV) nas comunidades de Lustal 2 e 
Tabela IV. Fases familiares por comunidades (\%). (Family fase by communities (\%)).

\begin{tabular}{lcccc}
\hline & Fase 0 & Fase 1 & Fase 2 & Fase 3 \\
Comunidades & $(\%)$ & $(\%)$ & $(\%)$ & $(\%)$ \\
Lustal 1* & 0,00 & 25,00 & 31,25 & 43,75 \\
Lustal 2* $^{*}$ & 11,11 & 0,00 & 55,56 & 33,33 \\
Tiassol $^{*}$ & 0,00 & 0,00 & 33,33 & 66,67 \\
Queimadas $^{\text {ns }}$ & 0,00 & 33,33 & 33,33 & 33,33 \\
Tapera* $^{*}$ & 0,00 & 25,00 & 43,75 & 31,25 \\
Junco* $^{*}$ & 6,25 & 12,50 & 18,75 & 62,50
\end{tabular}

${ }^{*}(p<0,0001)$; ${ }^{\text {ns }}$ ão significativo; Fase 0 : Casal jovem sem filhos; Fase 1: Família com filhos pequenos (idade pré-escolar ou o mais jovem com menos de 6 anos); Fase 2: Família com filhos em idade escolar (o mais jovem com menos de 16 anos); Fase 3: Família com filhos maiores de 16 anos.

Tapera as famílias encontram-se predominantemente na Fase 2, ou seja, famílias recém formadas, com filhos e filhas em idade préescolar ou o mais jovem com menos de 6 anos ( $<<0,0001$ para todas as partições com exceção de Queimadas onde $p=0,4215$ ) e níveis porcentuais de caráter intermediárioalto de educação informal para as senhoras, tal como se esperava (tabela V) $(p<0,0001)$. Em Lustal 1 e Queimadas se observa um equilíbrio entre a distribuição das fases familiares, significativo apenas para a primeira.
Nas comunidades restantes, Junco e Tiassol, se observam similaridades em relação às respectivas idades médias das mulheres rurais $(52,25$ e 52,44 anos) (tabela III) e em relação ao fato de que seus filhos(as) já estarem incorporados ao mercado de trabalho (tabela IV). No entanto, as respectivas porcentagens de educação informal das mulheres nessas comunidades são antagônicas, pois no Junco essa atinge sua maior expressão $(93,75 \%)$ e em Tiassol a menor $(55,56 \%)$ (tabela V). Em geral há um consenso sobre a existência de uma correlação positiva entre educação e crescimento econômico (Schultz, 1994). Esses resultados, provavelmente estão associados, portanto, ao fato de que na comunidade do Tiassol - contrariamente ao que ocorre na comunidade do Junco - há evidências de maior dinamismo econômico, vinculado às relações sociais de produção que incorporaram mão-de-obra assalariada em maior intensidade (Vidal e Alencar, 2009), desvinculando a mulher rural de atividades agropecuárias e possivelmente possibilitando à mesma a busca de melhor escolarização, já que a educação formal da mulher é pensada para permitir que ela obtenha autonomia e controle sobre sua vida (Basu, 2002). Efetivamente, é nessa comunidade (Tiassol) que se encontra o espectro mais diverso de graus de educação feminina:

Tabela V. Incidência do nível educacional por comunidade. (Educational level incidence by community).

\begin{tabular}{lccccccr}
\hline Educação (\%) & El & EFI & EFC & EMI & EMC & ESI & ESC \\
\hline Tapera $^{*}$ & 87,50 & 0,00 & 0,00 & 0,00 & 12,50 & 0,00 & 0,00 \\
Tiassol $^{*}$ & 55,56 & 22,22 & 0,00 & 0,00 & 0,00 & 11,11 & 11,11 \\
Lustal 2* $^{*}$ Queimadas $^{*}$ & 77,78 & 0,00 & 0,00 & 0,00 & 11,11 & 0,00 & 11,11 \\
Junco* $^{*}$ & 88,89 & 11,11 & 0,00 & 0,00 & 0,00 & 0,00 & 0,00 \\
Lustal 1 $^{*}$ & 93,75 & 0,00 & 0,00 & 0,00 & 0,00 & 0,00 & 6,25 \\
\hline
\end{tabular}

*( $p<0,0001)$; El:Ensino Informal ou lletrada; EFI: Ensino fundamental incompleto; EFC: Ensino fundamental completo; EMI: Ensino médio incompleto; EMC: Ensino médio completo; ESI: Ensino superior incompleto; ESC: Ensino superior completo. 
$55,56 \%$ educação informal, $22,22 \%$ ensino fundamental incompleto, $11,11 \%$ superior incompleto e $11,11 \%$ superior completo $(p<0,0001)$ (tabela V). Essa tendência demonstrada para o semiárido dos Inhamuns, vem sendo apontada na literatura européia há décadas (Arnalte-Alegre, 1980, para as mulheres espanholas; Haugen 1990, para as mulheres na Noruega e Shucksmith e Smith, 1991, para as mulheres da Escócia, entre outros). Ademais, o maior número de mulheres letradas está associado ao aumento da feminilização da força de trabalho não rural, clássica tendência apontada por autores na Europa desde a década de 60 do século passado (Barberis, 1963, para a Itália e Rodrigo, 1986, para Portugal, entre outros), ineditamente demonstrada para mulheres rurais do Sertão dos Inhamuns, Ceará, Brasil.

\section{RESPONSABILIDADESNA PRODUÇÃO ANIMAL E VEGETAL}

Em relação ao manejo com as aves, a participação da mulher foi destacável, pois se apresentou como um trabalho relevantemente feminino, seja como responsável única ou colaboradora em cinco comunidades, exceptuando-se a de Junco $(\mathrm{p}<0,0001)$ (tabela VI). Esses resultados são consis-

Tabela VI. Participação feminina (\%) por comunidade no manejo de aves, suínos, horta e outros trabalhos. (Women participation in the fowl, swines and vegetables garden-orchard management by communities).

\begin{tabular}{lcccccccc}
\hline \multirow{2}{*}{ Mulher } & \multirow{2}{*}{ Manejo } & & \multicolumn{7}{c}{ Comunidades rurais $(p<0,0001)$} \\
& & Lustal 1 & Lustal 2 & Tiassol & Queimadas & Tapera & Junco & Total \\
\hline Única responsável & \multirow{2}{*}{ Aves $^{1}$} & 22,22 & 8,89 & 11,11 & 15,56 & 17,78 & 24,44 & 100 \\
Colaboradora & & 25,00 & 25,00 & 5,00 & 5,00 & 40,00 & 0,00 & 100 \\
Ausente & & 10,00 & 0,00 & 30,00 & 10,00 & 0,00 & 50,00 & 100 \\
& & & & & & & & \\
Única responsável & Suínos $^{2}$ & 35,29 & 11,76 & 0,00 & 23,53 & 11,76 & 17,65 & 100 \\
Colaboradora & & 9,09 & 15,15 & 9,09 & 9,09 & 18,18 & 39,39 & 100 \\
Ausente & 28,00 & 8,00 & 24,00 & 8,00 & 32,00 & 0,00 & 100 \\
& & & & & & & & \\
Única responsável & Horta $^{3}$ & 21,21 & 15,15 & 0,00 & 3,03 & 30,30 & 30,30 & 100 \\
Colaboradora & & 7,14 & 0,00 & 0,00 & 7,14 & 42,86 & 42,86 & 100 \\
Ausente & 28,57 & 14,29 & 32,14 & 25,00 & 0,00 & 0,00 & 100 \\
& & & & & & & & \\
Única responsável & Outros $^{4}$ & 0,00 & 100,00 & 0,00 & 0,00 & 0,00 & 0,00 & 100 \\
Colaboradora & 22,03 & 13,56 & 15,25 & 13,56 & 22,03 & 13,56 & 100 \\
Ausente & 21,43 & 0,00 & 0,00 & 0,00 & 21,43 & 57,14 & 100 \\
\hline
\end{tabular}

${ }^{1}$ Sub-tarefas: limpeza e colocação dos cochos e recipientes de água, fornecimento de concentrados, volumosos e água; acompanhamento dos animais doentes e inválidos e retirada de esterco das instalações. ${ }^{2}$ Sub-tarefas: limpeza e colocação dos cochos e recipientes de água, fornecimento de concentrados, volumosos e água; acompanhamento da estação de monta, parições, dos animais doentes e inválidos e retirada de esterco das instalações. ${ }^{3}$ Sub-tarefas: irrigação manual ou mecânica, adubação manual ou mecânica, limpeza manual de ervas daninhas ou pulgões, semeadura manual, aplicação manual ou mecânica de pesticidas e colheita de futas, verduras, tubérculos e legumes. ${ }^{4}$ Outros trabalhos Sub-tarefas: trabalhos adminstrativos (cartas, formulários, pagamentos e atendimento telefônico), contabilidade, realização de cursos na área rural para a UPAF, venda de produtos para cooperatica ou consumidores em feiras e tarefas domésticas para os empregados da UPAF. 
tentes com os apresentados em estudo de campo realizado para se conhecer o sistema da produção e de utilização de aves domésticas por famílias rurais na região semiárida de Bangladesh. Enquanto o marido usava quantidades variáveis e inferiores de trabalho para a gerência das aves domésticas $(0,49$ unidades de trabalho ano - UTA masculino), a mulher rural era a maior responsável pelas atividades vinculadas aos mesmos, resultando em diferenças no total de mão de obra (1,49 UTAfeminino) (Rahaman, 2003). Uma distribuição do fator trabalho similar para mulheres e homens rurais em relação ao manejo de aves domésticas foi relatada previamente por Islam (1985) e Beg et al. (1994) também em Bangladesh. No manejo de suínos, as mulheres das comunidades rurais semiáridas cearenses sob análise também apresentam uma participação relevante, já que são as únicas responsáveis e/ou colaboradora em cinco comunidades, com exceção do Tiassol $(\mathrm{p}<0,0001)$ (tabela VI). Achados similares foram relatados por outros autores em regiões da Ásia. Responsabilidades com manejo de suínos também surgem como um aspecto importante das relações de gênero na Nova Guinea. O trabalho diário com manejo de suínos foi amplamente verificado como responsabilidade feminina nessa região asiática, enquanto o homem assume responsabilidades e domina as transações públicas vinculadas à suinocultura. Ainda, resultados recentes de um projeto para redução da pobreza por intermédio de pecuária executado na India (International Livestock Research Institute, 2008), evidenciou na região dos desertos frios de Andhra Pradesh, que a criação de suínos se destacou como a mais importante em comunidades rurais extremamente pobres. Nessas comunidades, a mulher rural, apesar de assumir responsabilidades relevantes com esses animais, representava pouco mais de $18 \%$ das proprietárias das Unidades Rurais e em conseqüência também não conseguiam os enlaces com a vida administrativa públi- ca. Alguns autores interpretam esse arranjo laboral como exploratório, pois a mulher trabalha cuidando dos suínos e o homem toma e utiliza esse trabalho em eventos públicos, caracterizando-se essas relações como desiguais e discriminatórias contra as atividades das mulheres (Josephides, 1985).

A atividade hortícola e de extrativismo de pomar também recebeu uma importante contribuição das mulheres em Tapera, Junco, Lustal 1 e Lustal 2. Exceções feitas a Tiassol e Queimadas, já que na primeira, não se cultivavam hortas e na segunda a participação como única responsável e/ou colaboradora é baixa $(\mathrm{p}<0,0001)$ (tabela VI). Nas UPAFs das primeiras comunidades, os vegetais mais cultivados eram a salsinha, cebolinha e alface, e as principais frutas extraídas: melão, manga e goiaba. Esses vegetais produzidos e/ou coletados eram periodicamente encaminhados para venda direta nas feiras semanais municipais. Nelas, as próprias mulheres apoiadas por membros da família, comercializavam diretamente o fruto de seu trabalho. Esses resultados são consistentes com os encontrados por autores que trabalharam em outras regiões semiáridas. Frankenberger et al.(1989), por exemplo, analisaram hortas familiares na Mauritânia, onde essa atividade era desenvolvida exclusivamente por mulheres cooperativadas, ou seja, seus cultivos hortícolas, compostos principalmente por melões, ervilhas selvagens, quiabo (Abelmoshus esculentus) e hibisco eram comercializados pelas próprias camponesas produtoras. Em outra área africana, Kumbija (Senegal), o impacto do trabalho feminino em projetos de horta nas condições de aridez da região foram estudados por Reynaud et al. (1989). Os mesmos observaram que as hortas eram usualmente instaladas após a colheita do milheto nos lotes de terra mais próximos às casas rurais, sendo que as mulheres cultivavam e vendiam os produtos das hortas, enquanto os homens construíam as cercas e lavravam a terra. Assim, observa-se tanto nos Inhamuns como nessas 
regiões da Africa, a predominância de vegetais comestíveis de origem doméstica, ou seja, autóctones, o que expressa a vertente bioregionalista da atividade hortifrutícola dessas regiões associada a climas semiáridos de zonas tropicais (Longhurst, 2006). Essas práticas das mulheres rurais se associam, portanto, à recuperação e conservação da biodiversidade local e delas mesmas como agentes sociais e econômicos, já que se encontram inseridas no contexto da cultura rural do semiárido acumulada durante séculos (Ayuntamiento de Bullas, 2007).

Observa-se que a mulher rural foi a única responsável por outros trabalhos apenas em Lustal 2 e como colaboradora se destaca em Lustal 1 e Tapera $(\mathrm{p}<0,0001)$ (tabela VI). Esses resultados são consistentes com os de Vidal (1995b) ao verificar que das 43 camponesas pertencentes a unidades familiares do vale médio do rio Ebro (semiárido de Aragón, Espanha), 60,94\% de las realizavam trabalhos administrativos.

Referente ao trabalho com o roçado (cultivos vegetais) e com os animais ruminantes - caprinos, ovinos e bovinos - foi observado em todas as comunidades rurais estudadas, que a participação da mulher rural foi pouco relevante, e quando houve, evidenciou-se como um trabalho apenas colaborativo com os demais respon-sáveis, a saber; marido, filhos(as), parentes e trabalhadores assalariados permanentes e/ou temporários $(p<0,0001)$ (tabela VII). No Tiassol não foi encontrada nenhuma mulher que participasse, mesmo que secundariamente, em atividades com ovinos e bovinos. A produção desses animais, vinculada à disponibilidade de terra, mobiliza fundamentalmente força de trabalho familiar e assalariada de tipo temporária no Distrito do Baixo Trici aqui estudado. Esses resultados mostram uma tendência diferente quando comparados aos de outras áreas semiáridas ou áridas do mundo (Sinn et al., 1999; Fakoya et al., 2006). Por exemplo, na região desértica de Rajasthan, Índia, Kumar (2004) conduziu estudo em 150 UPAFs para avaliar o envolvimento dos membros da família em trabalhos com ovinos. Seus resultados revelaram enquanto a mulher usa $49 \%, 25 \%$ e $16 \%$ de seu tempo com pastoreio, limpeza das instalações e cuidados dos

Tabela VII. Participaçãofeminina no manejo do roçado e de ruminantes. (Feminine participation on cultivation and ruminant cattle).

\begin{tabular}{|c|c|c|c|c|c|c|c|c|}
\hline & \multicolumn{2}{|c|}{$\begin{array}{c}\text { Roçado }^{1} \\
\text { Mulher (\%) }\end{array}$} & \multicolumn{2}{|c|}{$\begin{array}{c}\text { Caprinos }^{2} \\
\text { Mulher (\%) }\end{array}$} & \multicolumn{2}{|c|}{$\begin{array}{c}\text { Ovinos }^{2} \\
\text { Mulher (\%) }\end{array}$} & \multicolumn{2}{|c|}{$\begin{array}{c}\text { Bovinos }^{2} \\
\text { Mulher (\%) }\end{array}$} \\
\hline & Colabora & Ausente & Colabora & Ausente & Colabora & Ausente & Colabora & Ausente \\
\hline Lustal $1^{*}$ & 21,43 & 21,21 & 5,26 & 26,79 & 13,89 & 28,21 & 20,00 & 22,00 \\
\hline Lustal 2* & 2,38 & 24,24 & 21,05 & 8,93 & 5,56 & 17,95 & 16,00 & 10,00 \\
\hline Tiassol* & 4,76 & 21,21 & 10,53 & 12,50 & 0,00 & 23,08 & 0,00 & 18,00 \\
\hline Queimadas* & 16,67 & 6,06 & 36,84 & 3,57 & 22,22 & 2,56 & 20,00 & 8,00 \\
\hline Tapera* & 16,67 & 27,27 & 21,05 & 21,43 & 33,33 & 10,26 & 8,00 & 28,00 \\
\hline Junco* & 38,10 & 0,00 & 5,26 & 26,79 & 25,00 & 17,95 & 36,00 & 14,00 \\
\hline Total & 100,00 & 100,00 & 100,00 & 100,00 & 100,00 & 100,00 & 100,00 & 100,00 \\
\hline
\end{tabular}

${ }^{*} p<0,0001$; 'Sub-tarefas: preparação da terra e cuidados com o plantio; ${ }^{2}$ Sub-tarefas para ruminantes: limpeza e colocação de recipientes para forragens e água, recolhimento e corte de forragens; acompanhamento de estações de monta, parições, animais doentes e inválidos, fonecimento de concentrados e volumosos; sal mineral e água; retirada e colocação de animais no cercado e retirada de esterco das instalações. 
cordeiros, respectivamente, o homem utiliza $84 \%$ de seu tempo com pastoreio e $10 \%$ do mesmo com ordenha das ovelhas, revelando envolvimento em um menor número de tarefas com esses animais. Ainda, Vidal (1995b), ao realizar estudo em zona semiárida espanhola (Aragón) através de 75 mulheres rurais, objetivando analisar o trabalho feminino ao nível de Unidade de Produção, evidenciou que $56 \%$ delas encontravam-se relacionadas de maneira regular às tarefas manuais com o ovino, com o roçado e trabalhos administrativos em geral. Os resultados encontrados para Índia e Espanha mostram uma tendência oposta aos resultados apresentados pelo presente trabalho, ou seja, as mulheres da região semiárida dos Inhamuns no Estado do Ceará, ao dedicarse principalmente aos cuidados com animais monogástricos, horta e pomar, diferem do perfil de outras camponesas de distintas regiões desertificadas.

\section{CONCLUSÕES}

A partir desses resultados torna-se clara a importância que o trabalho feminino alcança para o funcionamento das unidades de produção agrária familiares nas seis comunidades rurais sob estudo no semiárido do Nordeste do Brasil. A determinação dos fatores explicativos evidencia as principais ocupações micro-econômicas femininas: aves e suínos, horta e pomar, que por serem considerados de menor valor quando comparados com o roçado e os ruminantes, os cônjuges das mulheres estão menos

\section{BIBLIOGRAFIA}

Arnalte-Alegre, E. 1980. Agricultura a tiempo parcial y transformaciones del campesinado. Agric. Soc., 17: 203-223.

Baliamoune-Lutz, M. and McGillivray, M. 2009. Does gender inequality reduce growth in SubSaharian African and Arab countries? Afr. Dev. Rev., 21: 224-242.

Banco Mundial. 1980. Lesotho: Agricultural sec- interessados em interferir com o controle feminino sobre aqueles meios de produção; podendo assim, a mulher manejar livremente os recursos advindos deles para as necessidades familiares.

Mesmo quando as mulheres e os homens rurais trabalham lado a lado ao longo da jornada de trabalho, os animais de curral aves e suínos - se evidenciaram tipicamente responsabilidade primária das mulheres, permitindo que essas elevam o nível de segurança alimentar da família através dos mesmos (Fakoya et al., 2006; Sinn et al., 1999).

Evidencia-se que o trabalho da mulher rural é em geral mais complexo quando comparado ao dos homens em regiões margializadas, pois ademais de se esperar delas a realização de certas tarefas produtivas específicas, ela compartilha, em diversos graus de responsabilidade, de outras tarefas rurais relacionadas ao gado maior (ruminantes) e labores tipicamente agrícolas como o cultivo de cereais.

As implicações para políticas públicas lato sensu, se relacionam à necessidade de se considerar os recursos e os conhecimentos das mulheres rurais de regiões desfavorecidas, sejam essas semiáridas ou não, enfocando assim, a pesquisa aplicada e a extensão participativa no melhoramento de tecnologias que valorizem e fortaleçam os componentes endógenos do sistema micro-econômico rural feminino. No âmbito da extensão participativa, a prioridade para a formação feminina associada idealmente ao trabalho cooperativo.

tor review. 1980. The role of women. Notes on women in development, n. 7. Office of the adviser on women in development. Wordl Bank. Washington, D.C. 47 pp.

Barberis, C. 1963. La femme dans l'agriculture italienne. Ét. Rur., 10: 13-20.

Basu, A.M. 2002. Why does education lead to low fertility? A critical review of some of the 
possibilities. World Dev., 30: 1779-1790.

Beg, M.A.H., Paul, D.C. and Ali, M. 1994. Poultry production and utilization system in Northern Part of Bangladesh. Bangladesh J. Training Dev., 9: 78-82.

Benevides, N. 2004. O perfil da mulher cacaueira: relatório referente à pesquisa realizada na região Sul da Bahia. Cad. CEAS, 211: 1-12.

Ayuntamiento de Bullas (Murcia). 2007. Anuncio de la feria de biodiversidad y culturas campesinas. Red de Agroecología y Ecodesarrollo de la Región de Murcia (RAERM). AgroCultura. Bullas. 12-14 Octubre. Murcia. España.

Câmara Federal Brasileira. 2004. Câmara de Deputados Federais, Brasília-DF. Mulher no sertão trabalha duro e ganha pouco. Jornal da Câmara, 10 Agosto. Ano 6 - № 1271. Brasília. D.F. Brasil.

Daniels, W. 1984. Bioestatística. 10ª ed. Limusa. México.

Esteves, R.C.V. 2002. Programa alfabetização solidária: uma estratégia de sucesso para a educação de jovens e adultos no Brasil. In: Anales del VII Congreso Internacional del CLAD sobre la Reforma del Estado y de la Administración Pública. 8-11 Octubre. Lisboa. Portugal.

FAO. 1996-2001. Food and Agricultural Organization of the United Nations. National sectoral report for Namibia- Women, agriculture and rural development. http: //www.fao.org/docrep/ X0174E/x0174e00.HTM (30/09/08).

Fakoya, E.O., Apantaku, S.O. and Adereti, F.O. 2006. Gender involvement in arable crop cultivation and its constributions to household food security in Ogun State, Nigeria. Res. J. Soc. Sci., 1: 1-4.

Fisher, I.R. 2001. A estrutura familiar da seca. Múltiplas trajetórias: estudos de gênero. $8^{\circ}$ encontro da REDOR. Anais... Fortaleza UFC/ NEGIF. pp. 169-191.

Fisher, I.R. 2002a. Reforma agrária: chão masculino, pão feminino. Texto para discussão $n=130$. FUNDAJ. Recife.

Fischer, I.R. 2002b. A mulher e a emergência da seca no NE do Brasil. Texto para discussão no 139. FUNDAJ. Recife.

Fisher, I.R., Melo, L.A. de, Viera, E. M. M. e Rocha, I. 2003. Capacitando mulheres chefes de família para gestão coletiva. In: Silva, M.D., I.S. Nery (Orgs.). Mulher Gênero e Globalização.
Teresina, PI. pp. 30-45.

Frankenberger, T.R., Stone, M.P. and Tejada, S.S. de 1989. Household vegetable gardens in Africa: Case studies from Mauritania and Lesotho. Arid Lands News Letter. N 29, Fall/Winter.

Furlan, R.M.C. 2007. Políticas públicas de educação de jovens e adultos nas escolas estaduais de São Paulo: avanços e desafios à sua consolidação. Dissertação de Mestrado. UNICIDUniversidade Cidade de SP.

Haugen, M. S. 1990. Female farmers in Norwegian agriculture. Sociol. Ruralis, 30: 197-209.

IBGE. 2008. Instituto Brasileiro de Geografia e Estatística. Censo demográfico. http://www. ibge.gov.br (01/02/11).

International Livestock Research Institute (ILRI). 2008. Livestock and poverty reduction in India: Findings from the ODI livelihood options project. Discussion paper, $\mathrm{n} \cong$ 8. Targeting and Innovation. 67 pp.

IPECE. 2008. Instituto de Pesquisa e Estratégia Econômica do Ceará. 2008. Anuário Estatístico. http://www.ipece.ce.gov.br (02/05/08).

Islam, F.A.M.N. 1985. Problem and prospect of livestock and poultry in rural area. Proceedings of the First Conference of Bangladesh Animal Husbandry Association. Bangladesh Agricultural Research Council (BARC). Farmgate. Dhaka.

Josephides, L. 1985. The production of inequality. Tavistock Editions. London.

Kumar, D. 2004. Role of rural women in sheep production in Rajasthan. Ind. J. Small Rum.,10: 176-179.

Longhurst, R. 2006. Plots, plants and paradoxes: contemporary domestic gardens in Aotearoa/ New Zealand. Soc. Cult. Geogr., 7: 45-67.

Martín-Guzman, M.P. 1988. Métodos estadísticos en el análisis regional. Est. Region., 22: 149-170.

ONU. 2000. Organização para as Nações Unidas. Declaração do milênio. Resolução aprovada pela Assembléia Geral (A/55/L.2) 55/2. http:// www.un.org/spanish/millenniumgoals/ ares552.html (04/11/09).

Osakabe, E. 2000. Pluriatividade da mulher européia e brasileira: uma abordagem inicial. 38응 Congresso da Sociedade Brasileira de Economia e Sociologia Rural. Anais... Rio de Janeiro. Brasil.

Pinstrup-Andersen, P. and Marito, C. 1984. 
Household vs. individual food consumption as indicators of the national impact of food policy. Paper presented at the Workshop Methods of measuring Intra-household resource allocation. Tuffs University. International Food Policy Research Institute. Washington D.C. 32 pp.

Rahaman, S.M.R. 2003. Family poultry production and utilization system in relation to landholding at Semi Arid Area of Bangladesh. International Livestock Research Institute Publications. Micro-Finance and Technical Support Project.

Reynaud, J. Brun, T. and Marek, T. 1989. Impact of a women's garden project on nutrition and income in Senegal. Aridlands Newsletter (Dryland Gerdening), № 29, Fall/Winter.

Rodrigo, I. 1986. Feminização da agricultura. Anál. Soc., 22: 643-652.

Rua, M. das G. e Abramovay, M. 2003. Companheiras de luta ou coordenadoras de panelas?: as relações de gênero nos assentamentos rurais. UNESCO. Brasília. Brasil. pp. 80-82.

Santos, M. de O. 2007. A mulher e a reprodução social da família. Rev. Ártemis, 7: 88-92.

Schultz, T.P.1994. Human capital investment in women and men: Micro and macro evidence of economic returns. International Center on Economic Growth. San Francisco. Occasional paper 44.

Shalander, K. 2008. Role of women in goat rearing in semi-arid parts of India: implications for their self empowerment and family's livelihood security. In: Anais da 9 ${ }^{a}$ Conferência Internacional sobre Caprinos. Querétaro. México.

Shucksmith, M. and Smith, R., 1991. Farm household strategies and pluriactivity in upland Scotland.
J. Agri. Econ., 42: 340-353.

Sinn, R., Ketzis, J. and Chen, T. 1999. The role of woman in the sheep and goat sector. Small Rum. Res., 24: 259-269.

Vidal, D. de L.1995a. Mujer rural y relaciones de género en el medio semi-árido de Aragón. 1. Conceptualizando el Nicho Laboral femenino en el marco de la Teoría Sistémica. En: Anales del II Congreso Nacional de Economía y Sociología Agraria. Valencia. España.

Vidal, D. de L. 1995b. Mujer rural y relaciones de género en el medio semi-árido de Aragón. 2. Análisis del trabajo femenino en la Unidad de Producción Agraria. En: Anales del II Congreso Nacional de Economía y Sociología Agraria. Valencia. España.

Vidal, D de L. 1995c. Mujer rural y relaciones de género en el medio semi-árido de Aragón. 3. La división por razones de sexo en el proceso de trabajo en la Unidad de Producción Agraria Familiar. En: Anales del II Congreso Nacional de Economía y Sociología Agraria. Valencia. España.

Vidal, D.de L. 2009. Relatório final do projeto de pesquisa e extensão rural: Autosustentação econômico-social de comunidades rurais através de cabras leiteiras naturalizadas em região semi-árida dos Inhamuns, Ce. Financiado pelo CNPq. Edital CT-AGRO/CT-HIDRO/MCT/ CNPq - no 019/2005. 175 pp.

Vidal, D. de L. e Alencar, J.V. de O. 2009. Sistemas agrários camponeses no semi-árido do Ceará: composição do fator trabalho, mecanização e produtividade. Em: Anais do Fórum do Semi-Árido. Universidade Estadual do Vale do Acaraú. Sobral. Ceará. Brasil. 